\title{
Modelling the Impact of Environmental Regulations on Bilateral Trade Flows: OECD, 1990-1996*
}

\author{
Mark N. Harris \\ Melbourne Institute of Applied Economic and Social Research, \\ The University of Melbourne, Australia; and Central European University, \\ Hungary \\ László Kónya \\ Victoria University, Australia \\ and \\ László Mátyás \\ Central European University, Hungary; Budapest University of Economics, \\ Hungary; \\ and Erudite, Universite Paris XII, France
}

Melbourne Institute Working Paper No. 11/00

ISSN 1328-4991

ISBN 0734014910

July 2000

* Mailing Address: L. Kónya, Victoria University, School of Applied Economics, PO Box 14428, Melbourne City, MC 8001, VIC Australia.

Email: Laszlo.Konya@vu.edu.au

Melbourne Institute of Applied Economic and Social Research

The University of Melbourne

Victoria 3010 Australia

Telephone (03) 83445330

Fax (03) 83445630

Email melb.inst@iaesr.unimelb.edu.au

WWW Address http://www.ecom.unimelb.edu.au/iaesrwww/ 


\begin{abstract}
Since the early seventies an increasing attention has been paid to the impact environmental policy has on foreign trade. One of the most important issues is whether countries with relatively strict environment al regulat ions tend to experience a deterioration of international competitiveness and thus a fall in the exports, and a rise in the imports, of the pollutionintensive commodities or, on the other hand, benefit from the improvement in environmental quality and are likely to develop new comparative advantages in the environmentally more sensitive industries. So far, most empirical studies have concluded that the proportion of environmental costs to the total production costs is still so marginal that environmental policies have hard ly any effect on comparative advantage patterns and thus on foreign trade. One of the few exceptions is Van Beers and Van den Bergh (1997), who found that stricter regulations have some negative impact on bilateral trade flows between OECD countries. The aim of this paper is to show that this outcome is part ly due to model mis-specification. The analysis is based on a triple indexed fixed-effects model and on its variants. It is found that, as soon as both the importing and exporting country specific effects are taken into consideration, the relationship between stricter regulations and foreign trade becomes statistically insignificant. This suggests that environmental costs do not have a real impact, neither negative nor positive, on foreign trade.
\end{abstract}

JEL classification: $\mathrm{C} 23$, F18

Key words: Gravity model, Panel data, Foreign trade, Environmental regulation, OECD countries. 


\section{Introduction}

Since the early sevent ies policy makers and academics alike, have been paying an increasing attention to the impact environmental policy might have on foreign trade. One of the main issues is whether countries with relativelystrict environmental regulations tend to experience a deterioration of international competitiveness and a decline of both local and foreign investment, at least in the pollution-intensive industries. Among others, Anderson and Blackhurst (1992), Dean (1992), Jaffe, Peterson, Portney and Stavins (1995), Levinson (1995), Van Beers and Van den Bergh (1996) and Xing and Kolstad (1996) provide interesting reviews of this issue.

It is a commonly held belief that the pollution-intensive industries of a country which imposes more stringent environmental regulations than its trading partners are likely to suffer a significant increase in production costs. Consequently, these industries either become less competitive internationally and lose some of their market share or, in order to avoid this loss, they migrate to countries with lower environmental standards. In any case, exports of pollution-intensive commodities of a country with relatively strict environmental regulations decrease, while their imports are expected to increase.

On the other hand, following for example Porter and Van der Linde (1995), this static view can be challenged on the ground that a country with relatively stringent environmental regulations can benefit from the improvement in environmental quality and is likely to develop new comparative advantages in the environmentally more sensitive industries. These advantages, in the long run, might more than offset the short-term losses. Moreover, even in the short run, as Van Beers and Van den Bergh (1997) point out, the negative effect of stringent environmental regulations on export flows and its positive effect on import flows can be blurre d by government interventions, such as subsidies to pollutionintensive industries, and import restrictions on foreign products which do not meet the higher than average domestic environmental standards. In addition to these environmental cost factors, industry loc ation will also be driven by other economic fundamentals such as: 
access to resources and markets, the supply and quality of labour, and transportation costs, for example. Indeed, the effect of these economic fundamentals may outweigh that of environmental cost factors.

So far empirical studies have not provided strong support for the hypothesis that relatively high environmental standards lead to the loss of competitiveness, and to the consequent decrease of exports and increase of imports. In fact, ap art from a few exceptions (Walter (1974) and Van Beers and Van den Bergh (1997)), most studies on different countries, industries and sample periods, conclude that environmental costs relative to total production costs are still marginal and have hardly any effect on comparative advantage patterns and therefore on foreign trade (see for example, Jaffe et al. (1995), Low (1992b), OECD [1985], Ratnayake (1998), Stevens (1993), Sorsa (1994), Tobey (1990) and Vallaru and Peterson (1997)).

The study which most strongly motivated this paper is that of Van Beers and Van den Bergh (1997). It analyses the impact of environmental regulations on bilateral trade flows for the cross section of 21 OECD countries in 1992. It is based on a gravity model, as developed by Tinbergen (1962) and Linnemann (1966), augmented by variables that measure the strictness of environmental regulations both in the importer and exporter countries. Two strictness measures of environmental regulations were used. The first one was based on the co mbination of seven ou tput-oriented environment al indicators, whilst the second was calculated from only two. Both of these measures, but especially the narrower one, are consistent with the Polluter Pays Principle. The model was estimated over three kinds of bilateral trade flows: total trade; pollution-intensive (or 'dirty') trade; and pollutionintensive trade related to non-resource based (or 'footloose') sectors. The results, based on the narrow environmental regulations strictness measure, can be summarised as follows (Van Beers and Van den Bergh, 1997, pp.41-42):

$i$. The analysis of total and 'footloose' trade supports "the hypothesis that a more stringent environmental policy exerts a negative influence on exports". However, environmental standards have no significant effect on 'dirty' exports in general. This 
means that the presence of resources is a more important factor determining competitiveness of pollution-intensive resource based industries than environmental standards.

ii. Relatively strict environmental regulations have negative impact on all three types of imports (total, 'dirty' and 'footloose'). This sugges ts that countries imposing more strict environmental regulations on their own producers, probably also erect non-tariff barriers to imports in order to protect domestic industries.

The aim of this paper is to find out how much these outcomes depend on the specification of traditional gravity models, such as the one used by Van Beers and Vanden Bergh (1997). For this reason, instead of the traditional double indexed cross-sectional approach, a three-dimensional panel data framework is employed, which allows for both importing and exporting country effects, as well as for time (or Business cycle) effects. Even if these additional specific effects are insignificant, the panel data set used is expected to be more reliable and enlightening than a simple cross-sectional data set, since bilateral trade, especially on the lower, two- and three-digit Standard International Trade Classification (SITC) levels, is often prone to strong annual fluctuations. As our analysis shows, as soon as these specific effects are taken into consideration, the relationship between stricter regulations and foreign trade becomes statistically insignificant. This suggests that environmental costs do not have a real impact, neither negative nor positive, on foreign trade.

The paper is structured as follows. The model is briefly described in Section 2 . Section 3 discusses the measurements and sources of the data used, with special regard to the strictness of environmental regulations. The empirical findings are summarised in Section 4. Finally, the concluding remarks can be found in Section 5. 


\section{The Model}

The basic model, hereafter referred to as $\operatorname{Model} B$, is a triple indexed generalisation of the model used by Van Beers and Van den Bergh (1997). It has the following form.

$$
\begin{aligned}
\ln I M P_{i j t} & =\beta_{0}+\beta_{1} \ln G D P_{i t}+\beta_{2} \ln G D P_{j t}+\beta_{3} \ln P O P_{i t}+\beta_{4} \ln P O P_{j t} \\
& +\beta_{5} \ln D I S T_{i j}+\beta_{6} A D J_{i j}+\beta_{7} E E C_{i j t}+\beta_{8} E F T A_{i j t}+\beta_{9} N A F T A_{i j t} \\
& +\beta_{10} \ln L A N D_{i}+\beta_{11} \ln L A N D_{j}+\beta_{12} \ln S C_{i t}+\beta_{13} \ln S C_{j t}+u_{i j t}
\end{aligned}
$$

where: In den otes natural logarithm;

$I M P_{i j t}$, the imports of country $i$ from country $j$ in year $t$;

$G D P_{i t}, G D P_{j t}$, the GDPs of countries $i$ and $j$, respectively, in year $t$;

$P O P_{i}, P O P_{j t}$, the populations of countries $i$ and $j$, respectively, in year $t$;

$D I S T_{i j}$, the distance between countries $i$ and $j$;

$A D J_{i j}$, a dummy variable, equal to 1 if countries $i$ and $j$ are adjacent, i.e. share a common land border, and zero otherwise;

$E E C_{i j t}$, a dummy variable, equal to 1 if countries $i$ and $j$ are both members of the EEC in year $t$ and zero otherwise;

$E F T A_{i j t}$, a dummy variable, equal to 1 if countries $i$ and $j$ are both members of the EFTA in year $t$ and zero otherwise;

$N A F T A_{i j t}$, a dummy variable, equal to 1 if countries $i$ and $j$ are both members of the NAFTA in year $t$ and zero otherwise;

$L A N D_{i}, L A N D_{j}$, the land areas of countries $i$ and $j$, respectively;

$S C_{i t}, S C_{j t}$, scores measuring the relative strictness of environmental regulations in countries $i$ and $j$, respectively, in year $t$;

$u_{i j t}$, white noise disturbance term; and

$i=1, \ldots, N, j=1, \ldots, i-1, i+1, \ldots, N, t=1, \ldots, T$.

In this model, $G D P_{i}$ measures the potential demand of the importing country, while $G D P_{j}$ represents the potential supply of the exporting country. Ther efore, the corresponding 
slope parameters, $\beta_{1}$ and $\beta_{2}$, are expected to be positive. $P O P_{i}$ and $P O P_{j}$ are used to capture the effects of economies of scale in the importing and exporting countries, res pectively. Since countries with large populations tend to be more self-reliant, one might expect $\beta_{3}$ and $\beta_{4}$ to be negative. However, the expansion of the scale of productive capacity causes longrun average costs to fall, giving more populous countries a competitive edge in exporting, so that $\beta_{4}$ could also be positive.

$D I S T_{i j}$ is a proxy for resistance to trade, thus it is anticipated that $\beta_{5}$ will be negative. The $A D J_{i j}, E E C_{i j}, E F T A_{i j}$ and $N A F T A_{i j}$ dummy variables indicate whether the trading partners have a relatively stronger bond, so that $\beta_{6}, \ldots, \beta_{9}$ are expected to be positive. $L A N D_{i}$ and $L A N D_{j}$ are the sheer sizes of the importing and exporting countries, res pectively. Their slope parameters, $\beta_{10}$ and $\beta_{11}$, are probably negative since larger countries are more diverse and potentially richer in natural resources. One might also argue, however, that $\beta_{11}$ is positive since larger countries tend to possess more natural resources and a bigger exporting capacity.

Finally, $S C_{i}$ and $S C_{j}$, measure how strict the environmental regulations are in the importer and exporter countries. In line with the assumption that strict environmental standards lead to relatively lower exports but higher imports, one might expect $\beta_{12}$ to be positive and $\beta_{13}$ to be negative. However, as mentioned earlier, $\beta_{12}$ could be negative, either due to subsidization of local production suffering from the higher than average domestic environmental standards, or as a result of trade barriers imposed to imports from countries with lower environmental standards. Similarly, $\beta_{13}$ could be positive for countries which have a comparative advantage in the environmentally more sen sitive ind ustries. In summary, it is hypothesized that the $\beta_{1}, \beta_{2}, \beta_{6}, \beta_{7}, \beta_{8}, \beta_{9}$ slope parameters are positive, $\beta_{3}, \beta_{5}, \beta_{10}$ are negative, while the signs of $\beta_{4}, \beta_{11}, \beta_{12}$ and $\beta_{13}$ are ambiguous.

The cross sectional specification used by Van Beers and Van den Bergh (1997) is a special case of (1), with $T=1$. It is denoted as Model $A .{ }^{1}$ Apart from Models $A$ and $B$,

\footnotetext{
${ }^{1}$ In this model $\beta_{9}=0$ because NAFTA became effective only in 1994.
} 
which do not t ake any specific effects into consideration, three further generalisations of (1) are also considered. The first one, Model C, allows for import er co untry effects by including $\alpha_{i}$, into Model B. This extra term represents all the factors that might have some influence on imports, but are not explicitly taken into consideration in (1), and it permits average propensities to import to differ across countries. The second one, Model D, additionally allows for exporter country effects. Therefore, it has two extra terms, $\alpha_{i}$ for the importer country effect and $\gamma_{j}$ for the exporter country effect. Finally, the third one, Model E, has three extra terms, $\alpha_{i}, \gamma_{j}$ and $\lambda_{t}$, with the last one serving to capture any time (business cycle) effects on bilateral trade flows.

In matrix form the most ge neral specification (Model E) can be written as

$$
y=D_{N} \alpha+D_{J} \gamma+D_{T} \lambda+Z \beta+u
$$

where: $y$ is the vector of observations of the dependent variable,

$$
y=\left[y_{121}, y_{122}, \ldots, y_{12 T}, y_{131}, \ldots, y_{13 T}, \ldots, y_{N 11}, \ldots, y_{N 1 T}, \ldots, y_{N(N-1) 1}, \ldots, y_{N(N-1) T}\right] ;
$$

$Z$ is the matrix of observations of the explanatory variables in (1), including the constant term, organised in a similar wayto $y ; \alpha=\left[\alpha_{1}, \alpha_{2}, \ldots, \alpha_{N}\right]^{\prime}, \gamma=\left[\gamma_{1}, \gamma_{2}, \ldots, \gamma_{N}\right]^{\prime}, \lambda=\left[\lambda_{1}, \lambda_{2}, \ldots, \lambda_{T}\right]^{\prime}$, and $\beta=\left[\beta_{0}, \beta_{1}, \ldots, \beta_{K}\right]$ ' are parameter or disturbance vectors; $K$ is the number of explanatory variables; and $u$ is the vector of disturbances. $D_{N}, D_{T}$ and $D_{J}$ are dummy variable matrices defined as $D_{N}=I_{N} \otimes l_{N T}$ and $D_{T}=l_{N^{2}} \otimes I_{T}$, where $l$ is a vect or of ones with its size in the index. The structure of the $D_{J}\left(\left(N^{2} \times T\right) \times N\right)$ matrix is a bit more complex such that

$$
\begin{aligned}
& D_{J}=\left(\begin{array}{c}
\tilde{I}^{(1)} \\
\vdots \\
\tilde{I}^{(N)}
\end{array}\right) \quad \text { where } \\
& I^{(1)}=\left(\begin{array}{lll}
0 & I_{N}
\end{array}\right) \quad \text { and } \quad \tilde{I}^{(1)}=I^{(1)} \otimes l_{T} \\
& I^{(2)}=\left(\begin{array}{ccc}
1 & & \\
& 0 & I_{N-1}
\end{array}\right) \quad \text { and } \quad \tilde{I}^{(2)}=I^{(2)} \otimes l_{T}
\end{aligned}
$$




$$
I^{(N)}=\left(\begin{array}{ccc}
I_{N-1} & 0 & \\
& & 1
\end{array}\right) \quad \text { and } \quad \tilde{I}^{(M)}=I^{(N)} \otimes l_{T}
$$

Imposing the $\lambda_{t}=0 \forall_{t}$ restrictions on (2) yields Model D. Model C requires $\gamma_{j}=\lambda_{t}=0 \forall_{j, t}$, while in Model $B$ all three vectors are assumed to be null vectors.

In Models $C$ - $E$, the $\alpha_{i}, \gamma_{j}$ and $\lambda_{t}$ specific effects can be treated in two different ways, either as random variables (an error components approach) or fixed parameters (a fixed effects approach). Given that a specific aim is to analyse these effects, they are treated as fixed unknown parameters. Note, however, that similarly to these fixed specific effects, some of the independent variables are one dimensional, that is they vary across countries, but not over time. As a result, Models $C$-E cannot be estimated without appropriate restrictions. In Model CLAND ${ }_{i}$ would be perfectly collinear with $\alpha_{i}$, so it has to be dropped from the specification. Similarly, Models $D$ and $E$ have to be estimated without $L A N D_{i}$ and $L A N D_{j}$. The other independent variables change in at least two dimensions, so they do not cause perfect multicollinearity. The $i j$-indexed $D I S T$ and $A D J$ variables, for example, w ould be perfectly multicollinear with $\alpha_{i} \times \gamma_{j}$, but not with $\alpha_{i}+\gamma_{j}$. Note also that allof the models have a constant term. Therefore, again in order to avoid perfect multicollinearity, at least one dummy variable has to be dropped from each set, i.e. there cannot be more than $N-1$ importer country dummies, $N-1$ exporter country dummies and $T-1$ year dummies.

\section{The Data}

The data utilised in this study is comprised of annual measures for seven years, 1990-1996, on 24 OECD countries (Australia, Austria, Belgium-Luxemburg², Canada, Denmark, Finland, France, Germany, Greece, Ice land, Ireland, Italy, Japan, Mexico, the Netherlands, New Zealand, Norway, Portu gal, Spain, Sweden, Switzerland, Turkey, the United Kingdom

\footnotetext{
${ }^{2}$ In international trade statistics Belgium and Luxemburg are usually treated as a single country.
} 
and the USA). ${ }^{3}$ Similarly to Van Beers and Van den Bergh (1997), all five models were estimated over three different kinds of bilateral trade flows. The precise definitions of the quantitative variables ${ }^{4}$ and data sources are:

$T I M P_{i j t}$, total imports of country $i$ from country $j$ in year $t$ in terms of thousands of 1990 US dollars. The import data in thousands of US dollars are from the United Nations Commodity Trade Statistics, Statistical Papers, Series D (1990, 1991, 1992, 1993, 1994, 1995 and 1996). ${ }^{5}$ These current dollar import figures were deflated by deflators for imports of goods and services obtained from the World Bank World Tables.

$D I M P_{i j t}$, similar to TIMP, but instead of total imports it measures only the imports of pollution-intensive sectors. On the basis of SITC (version 3) the following industries are classified as 'dirty' 251 (Pulp and Waste Paper); 334 (Petroleum Products); 335 (Residual Petroleum Products); 51 (Organic Chemicals); 52 (Inorganic Chemicals);562 (Fertilizers); 59 (ChemicalMaterials); 634 (Veneers,Plywood); 635 (Wood Manufactures); 64 (Paper, Paperboard); 661 (Lime, Cement, Construction Materials); 67 (Iron and Steel); 68 (Non-Ferrous Metals); and 69 (Metals Manufactures).

$F L I M P_{i j t}$, similar to DIMP, but only for the non-resource based pollution-intensive ('footloose') sectors, i.e. for 59, 661, 67 and 69.

$G D P_{i t}, G D P_{j t}$, GDPs of countries $i$ and $j$ in year $t$ in terms of billions of 1990 US dollars. Two different series were experimented with, based on purchasing-power parities $(G D P 1)$ and on exchange rates (GDP2), respectively. Both series are from Energy

\footnotetext{
${ }^{3}$ At the moment the OECD has 29 members. However, we have considered on ly those which join ed the organisation before 1995, so we have disregarded the Czech Republic, Hungary, Korea and Poland. in Section 2.

${ }^{4}$ The exact descriptions of the $A D J_{i j}, E E C_{i j t}, E F T A_{i j t}$ and $N A F T A_{i j t}$ dummy variables can be found

${ }^{5}$ Unfortunately, this data source proved to be a bottleneck in this project. At the time of data collection (the second half of 1999) detailed trade data were still not available for after 1996.

${ }^{6}$ This definition of 'dirty' SITC categories is from Low (1992a).
} 
Balances of OECD Countries, 1996-1997, International Energy Agency, 1999. $P O P_{i t}, P O P_{j t}$, populations of countries $i$ and $j$ in year $t$ (Source: Energy Balances of OECD Countries, 1996-1997, International Energy Agency, 1999).

$D I S T_{i}$, average distance between the major economic areas of countries $i$ and $j$ in nautical miles. It has been calculated following Linnemann (1966). The distances between major ports are extracted from $h t t p: / / w w w . p o r t s . c o m$, the average distances between the ports and the most important economic areas are from Linnemann (1966, pp.222-226).

$L A N D_{i}, L A N D_{j}$, land areas of country $i$ and $j$ in 1,000 ha, obtained from the Human Development Report, 1996, United Nations Development Programme.

$S C_{i t}, S C_{j t}$, measure of the relative strictness of domestic environmental regulations in countries $i$ and $j$ in year $t$.

Since $S C$ is the most crucial variable in the analysis, it warrants further discussion. As already mentioned, Van Beers and Vanden Bergh (1997) constructed two environmental regulations strictness measures for 1992. The first one was based on seven output-oriented societal indicators which, in different ways, try to assess the overall effect of the environmental regulations and the corresponding compensating subsidies, if there are any. ${ }^{7}$ Since most of these indicators are publishe d only irregularly, it is not possible to develop this first type of strictness measures for each year 1990-1996. The second, narrower measure, was composed from only two indicators - from the level of energy intensity in 1980 and from the change of energy intensity from 1980 to 1991 - by a ranking procedure. ${ }^{8}$ This second approach was followed.

Six strictness measures were experimented with. Each one of these was based on one of the following two indicators published in the Energy Balances of OECD Countries,

\footnotetext{
${ }^{7}$ These indicators are the following (Van Beers and Van den Bergh, 1997, p. 34): protected areas as a percentage of national territory in 1990; market share of unleaded petrol in 1990; recycling ra te of paper in 1990; recycling rate of glass in 1990; percentage of population connected to sewage treatment plant in 1991; level of energy intensity in 1980; and change of energy intensity 1980-1991.

${ }^{8}$ See Van Beers and Van den Bergh (1997), p. 35.
} 
1993-1994 and 1996-1997, International Energy Agency, 1996 and 1999:

$E C_{i t}$, total final consumption of energy (Mtoe) in country $i$ in year $t$; and $E S_{i t}$, total primary energy supply (Mtoe) in country $i$ in year $t$.

These absolute indicators were compared to GDP1, to GDP2 and to $P O P$, respectively, and from the resulting relative measures, index numbers were calculated for 1990-1996 $(1980=100)$. Then, for each year, the countries were ranked (from the worst to the best), both upon the static and dynamic measures. For each country the two ranks were summed and upon this compound measure the countries were ranked again. In this way six sets of ranks were obtained for 1990-1996. Finally, these ranks were divided by the number of countries in order to derive six sets of strictness measures ranging between 0 (no environmental regulations) and 1 (strict environmental regulations).

The rankings for 1992 are shown in Table 1, along with the one developed by Van Beers and Van den Bergh (1997). These rankings are similar, but not identical, especially not so for Australia, France, Japan, Mexico, the Netherlands, Norway, Spain, Sweden, Switzerland and Turkey. Measuring the strength of association between these rank orders by Kendall's $\tau_{b}$ and Spearman's $\rho$ coefficients, it was found that neither $R_{E C, G D P 2}$ nor $R_{E S, G D P 2}$ is significantly correlated with $R_{E C, P O P}$ and $R_{E S, P O P}$, not even at the $10 \%$ level. ${ }^{9}$ This suggests that the estimation results of (2), or any of its variants, might strongly depend on the choice of the strictness measure. The comparison of these rankings to the one created by Van Beers and Van den Bergh (1997), $R_{B B}$, also revealed that $R_{E S, G D P 2}$ is the most similar to $R_{B B}$, followed by $R_{E S, G D P 1}$ and $R_{E C, G D P 2}$.

For this reason, although each model was estimated using allsix rankings, attention is focussed on the results based on total primary energy supply and GDP deflated by exchange rates. The corresponding ranks, $R_{E S, G D P 2}$, for each year, are illustrated in Figure 1. Clearly, the relative strictness of environmental regulations changed significantly during the sample period, most notably in Finland, France, Ireland, Japan, Norway, Spain, Sweden

\footnotetext{
${ }^{9}$ The complete set of strictness measures and the bivariate rank correlation coefficients for 1992 can be obtained from the authors on request.
} 
Table 1

Rankings Representing Environmental Regulations Strictness, 1992

\begin{tabular}{|c|c|c|c|c|c|c|c|}
\hline \multirow{2}{*}{ Country } & \multicolumn{7}{|c|}{ Ranks (from worst to best) } \\
\hline & $R_{B B}$ & $R_{E C, G D P 1}$ & $R_{E C, G D P 2}$ & $R_{E C, P O P}$ & $R_{E S, G D P I}$ & $R_{E S, G D P 2}$ & $R_{E S, P O P}$ \\
\hline Australia & 2 & 7 & 8 & 17 & 6 & 7 & 15 \\
\hline Austria & 17 & 17 & 18 & 14 & 23 & 22 & 21 \\
\hline Belg.-Lux. & 17 & 11 & 13 & 8 & 9 & 9 & 5 \\
\hline Canada & 7 & 5 & 9 & 8 & 7 & 8 & 13 \\
\hline Denmark & 19 & 24 & 24 & 22 & 24 & 24 & 21 \\
\hline Finland & 4 & 3 & 5 & 2 & 3 & 10 & 5 \\
\hline France & 12 & 15 & 17 & 20 & 10 & 14 & 5 \\
\hline Germany & 21 & 22 & 23 & 23 & 20 & 23 & 21 \\
\hline Greece & 6 & 4 & 7 & 11 & 5 & 4 & 12 \\
\hline Iceland & - & 1 & 3 & 1 & 1 & 3 & 1 \\
\hline Ireland & 13 & 20 & 20 & 12 & 19 & 19 & 13 \\
\hline Italy & 13 & 19 & 15 & 17 & 20 & 19 & 20 \\
\hline Japan & 19 & 23 & 22 & 8 & 22 & 21 & 8 \\
\hline Mexico & - & 5 & 1 & 24 & 8 & 2 & 24 \\
\hline Netherlands & 16 & 7 & 10 & 12 & 17 & 16 & 17 \\
\hline New Zealand & 1 & 2 & 1 & 2 & 2 & 1 & 2 \\
\hline Norway & 9 & 11 & 21 & 4 & 11 & 18 & 3 \\
\hline Portugal & 2 & 11 & 4 & 6 & 13 & 5 & 9 \\
\hline Spain & 8 & 17 & 12 & 6 & 11 & 10 & 9 \\
\hline Sweden & 4 & 7 & 18 & 14 & 4 & 12 & 4 \\
\hline Switzerland & 13 & 11 & 16 & 4 & 15 & 16 & 15 \\
\hline Turkey & - & 21 & 5 & 20 & 18 & 6 & 17 \\
\hline$U K$ & 11 & 10 & 10 & 17 & 16 & 15 & 17 \\
\hline USA & 9 & 15 & 14 & 14 & 13 & 12 & 11 \\
\hline
\end{tabular}


Figure 1: Ranks Based on ES and GDP2

(from worst to best)

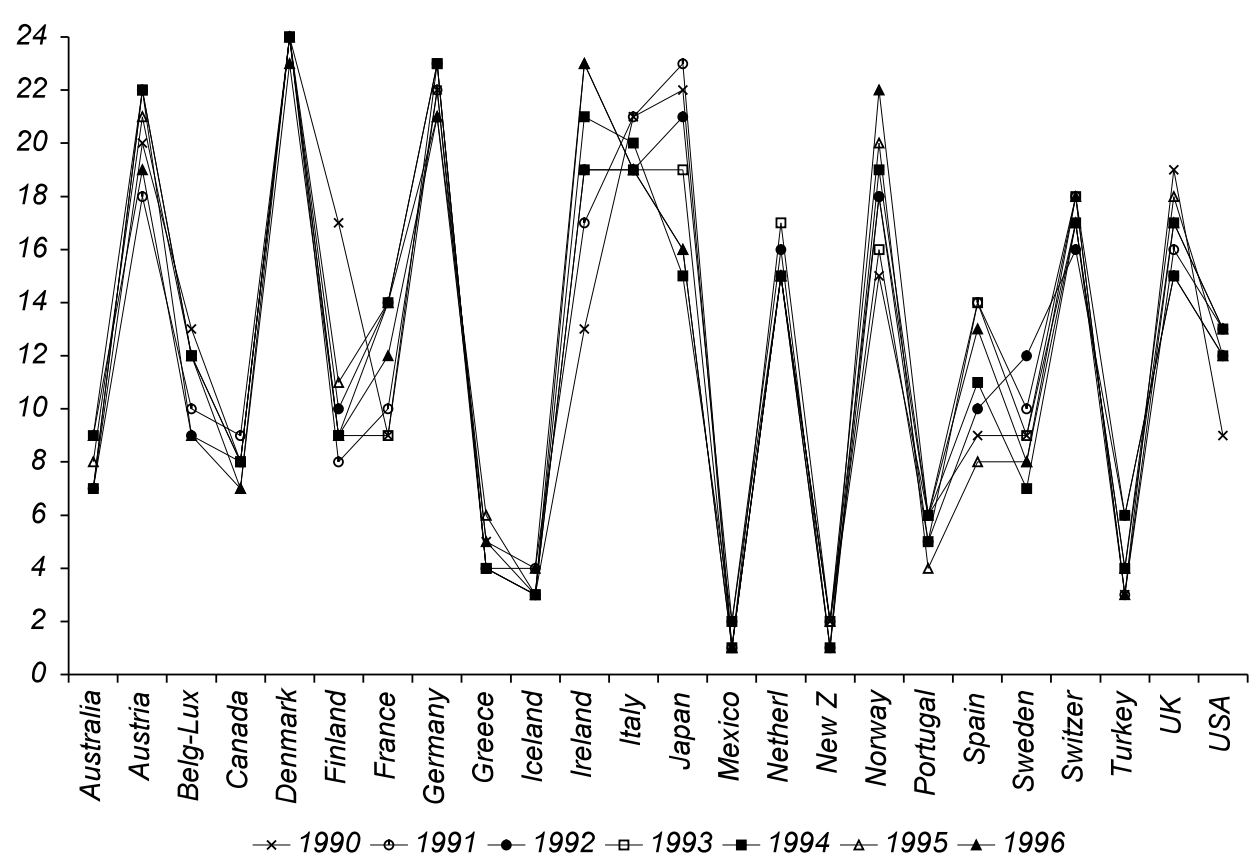

and the UK. This fact further highlights the potential advantage of a panel-data analysis over a purely cross-sectional one, which is based on a single snapshot in time and thus lacks dynamics.

\section{Estimation Results}

Before reviewing the most important outcomes of the analysis, there are two remarks to be made. Firstly, since heterosced asticity is very likely, the usual $t$-statistics were computed from heteroscedasticity-consistent standard errors. Secondly, some of the bilateral trade flows are zero, for which the dependent variable, $\ln I M P$, is not defined. In order to circumvent this problem, all import figures were inflated by unity. ${ }^{10}$ In spite of this, due to the fact that $\ln (I M P+1)$ might be zero, the OLS estimators are still potentially biased, so

\footnotetext{
${ }^{10}$ Given the magnitudes of TIMP, DIMP and FLIMP, this manipulation assures that the logarithms exist without having any statistical effect on the estimates.
} 
Tobit estimato rs were also expe riment ed with and all non-po sitive dependent variable values were censored. However, as the proportion of censored observations is small, the OLS and Tobit results are very similar, so only the most important OLS results are discussed in this paper. ${ }^{11}$

Five models, Models A-E, for three types of bilateral trade flows, using six different environmental regulations strictness measures were estimated. ${ }^{12}$ The OLS results based on GDP2 and $R_{E S, G D P 2}$ are summarised in Tables 2-4. Table 2 contains the findings for TIMP, Table 3 for DIMP and Table 4 for FLIMP. In each table the first set of results is from a cross-sectional analysis for 1992, similar to the one performed by Van Beers and Van den Bergh (1997), and the other four sets are the estimation results of (2) and its generalisations over the whole sample period. The outcomes of various $F$-tests for the joint significance of the additional dummy variables are also presented in these tables. ${ }^{13}$

\section{Total Imports}

In Models $A$ and $B$, which do not allow for any specific effects, all slope estimates but two are significant in the expected direction. In particular, both importing and exporting country GDPs, adjacency and EEC or NAFTA membership seem to be positively related to total bilateral import flows. On the other hand, importing and exporting country populations and land sizes, as well as the distance between these countries, exert negative impacts on total imports. The EFT A dummy is insignificant in Model A, but it is weakly significant in the unexpected, i.e. negative, direction in Model B. Most importantly, the relative strictness of environmental regulations in the importing country has a strongly significant negative effect

${ }^{11}$ There are only 2 censored TIMP observations, 81 censored DIMP observations and 127 FLIMP observations, while the sample size is 3864 .

${ }^{12}$ For brevity, not all details are reported in this paper, but are available on request.

${ }^{13}$ Note that these $F$-tests are strictly evalua ting the net effect of the additional set of dummies and that of the left out perfectly collinear variable(s). 
Table 2

OLS Estimation Results for TIMP

(GDP2 and $\left.R_{E S, G D P 2}\right)$

\begin{tabular}{|c|c|c|c|c|c|}
\hline \multirow{2}{*}{ Variable } & \multicolumn{5}{|c|}{ Specification } \\
\hline & Model A & Model B & Model C & Model D & Model E \\
\hline Constant & $22.069^{* * * *}$ & $23.848^{* * * *}$ & $174.002^{* * *}$ & $147.202^{* * * *}$ & $171.673^{* * * *}$ \\
\hline $\ln G D P_{i t}$ & $1.459^{* * *}$ & $1.677^{* * *}$ & $2.265^{* * *}$ & $2.174^{* * *}$ & $1.796^{* * *}$ \\
\hline $\ln G D P_{j t}$ & $1.491^{* * *}$ & $1.431^{* * *}$ & $1.481^{* * *}$ & $1.063^{* * *}$ & $0.685^{*}$ \\
\hline $\ln P O P_{i t}$ & $-0.535^{* * *}$ & $-0.760^{* * *}$ & $-9.902^{* * *}$ & $-10.300^{* * *}$ & $-10.900^{* * *}$ \\
\hline $\ln P O P_{j t}$ & $-0.580^{* * *}$ & $-0.541^{* * *}$ & $-0.572^{* * *}$ & 1.684 & 1.077 \\
\hline $\ln D I S T_{i j}$ & $-0.689^{* * *}$ & $-0.627^{* * *}$ & $-0.736^{* * *}$ & $-0.948^{* * *}$ & $-0.949^{* * *}$ \\
\hline $\mathrm{ADJ}_{\mathrm{ij}}$ & $0.488^{* * *}$ & $0.588^{* * *}$ & $0.500^{* * *}$ & $0.351^{* * *}$ & $0.350^{* * *}$ \\
\hline$E E C_{i j t}$ & $0.401^{* * *}$ & $0.387^{* * *}$ & $0.123^{* * *}$ & $0.104^{* * *}$ & $0.097^{* * * *}$ \\
\hline EFTA $_{\mathrm{ijt}}$ & 0.004 & $-0.122^{*}(?)$ & 0.082 & $0.123^{* *}$ & $0.131^{* *}$ \\
\hline$N A F T A_{i j t}$ & na & $0.751^{* * *}$ & $1.034^{* * *}$ & $0.798^{* * *}$ & $0.793^{* * * *}$ \\
\hline $\ln L A N D_{i}$ & $-0.069^{* *}$ & $-0.082^{* * *}$ & na & na & na \\
\hline $\ln L A N D_{j}$ & $-0.097^{* * *}$ & $-0.097^{* * *}$ & $-0.091^{* * *}$ & na & na \\
\hline $\ln S C_{i t}$ & $-0.246^{* * *}$ & $-0.252^{* * *}$ & 0.068 & 0.067 & 0.092 \\
\hline $\ln S C_{j t}$ & -0.029 & 0.012 & -0.049 & -0.026 & -0.001 \\
\hline$\overline{D_{i}}$ & na & na & - & - & - \\
\hline$D_{j}$ & na & na & na & $\begin{array}{l}2,5,6,9,10 \\
13,18,21\end{array}$ & $2-24$ \\
\hline$D_{t}$ & na & na & na & na & $2-5$ \\
\hline Observations & 552 & 3864 & 3864 & 3864 & 3864 \\
\hline$R S S$ & & 2867.783 & 2285.79 & 1748.068 & 1744.098 \\
\hline adj. $R^{2}$ & 0.859 & 0.855 & 0.884 & 0.911 & 0.911 \\
\hline$F$-tests $^{\mathrm{d}}$ & df1 & $\mathrm{df} 2$ & $F$-statistic & & \\
\hline$C$ vs $B$ & 22 & 3828 & $44.299^{* * *}$ & & \\
\hline$D$ vs $B$ & 44 & 3806 & $55.405^{* * *}$ & & \\
\hline$D$ vs $C$ & 22 & 3806 & $53.216^{* * *}$ & & \\
\hline$E$ vs $B$ & 50 & 3800 & $48.963^{* * *}$ & & \\
\hline$E$ vs $C$ & 28 & 3800 & $42.151^{* * *}$ & & \\
\hline$E$ vs $D$ & 6 & 3800 & 1.442 & & \\
\hline
\end{tabular}


a) $* * *, * *$ and $*$ indicate significance at the $1 \%, 5 \%$ or $10 \%$ level, respectively, while (?) shows that the slope estimate is significant in a perverse direction.

b) $D_{i}, D_{j}$ and $D_{t}$ denote the sets of insign ificant (at the $10 \%$ level) importer country, exporter country and time dummy variables. The countries are numbered as: 1, Australia; 2, Austria; 3, Belgium-Luxemburg; 4, Canada; 5, Denmark; 6, Finland; 7, France; 8, Germany; 9, Greece; 10, Iceland; 11, Ireland; 12, Italy; 13, Japan; 14, Mexico; 15, the Netherlands;16, New Zealand; 17, Norway; 18, Portugal; 19, Spain; 20, Sweden; 21, Switzerland; 22, Turkey; 23, the United Kingdom; 24, the USA.

c) Due to the different sample sizes the first adjusted $R^{2}$ value is not comparable with the other four.

d) Model X versus Model Y.

on total bilateral import flows, while the regulations in the exporting country seem to be uninfluential. This is in sharp contrast with the findings of Van Beers and Van den Bergh (1997) who detected significant negative relationships between total bilateral imports and the strictness of environmental regulations in both the importing and exporting countries. ${ }^{14}$

Considering the other three specifications, three notable important differences in the results are apparent. Firstly, as both the importing and exporting country effects are taken into consideration, the exporting country population loses its significance. Secondly, the EFTA dummy becomes significant in the expected direction. Thirdly, both stringency measures turn out to be insignificant, suggesting that they have no real impact on bilateral trade. It is also clear from the general $F$-tests that both the importing country dummy variables and the exporting country dummy variables are jointly significant. These results suggest that Models $A$ and $B$ are incorrectly specified. In those models the omitted specific effects might be assumed by the other independent variables, most not ably by $\ln P O P_{j t}$ and $\ln S C_{i t}$, making them appear significant. ${ }^{15}$

Judging the quality of the se models by the adjusted coefficient of determination, all

\footnotetext{
${ }^{14}$ However, as our analysis with the different stringency measures shows, the apparent effect of environmental regulations in the exporting country strongly depends on the mea sure used. If, for example, instead of $R_{E S, G D P 2}$ we use $R_{E C, G D P 1}$, then $\ln S C_{j t}$ seems to exert a sign ifican t positive effect on $\ln T I M P_{i j t}$, while using $R_{E S, P O P}$ or $R_{E C, P O P}$ the effect is insignificant in Model A, but significantly negative in Model $B$.

${ }^{15}$ There is only one type of stringen cy measures which leads to a different outcome: using $R_{E C, G D P 2}$ strictness in the importing country has a significant negative effect on total bilateral trade in all five specifications. Apart from this important difference, the estimation results are very similar.
} 
five specifications have reasonable explanatory power. Model $D$ is the best accounting for about $91 \%$ of the total variation in the logarithm of $T I M P_{i j t}$. Although the most general specification, Model E, does not perform better, it still provides an interesting new piece of information. The year dummy variables are jointly insignificant, but the only individually significant one causes all exporting country effects to become negligible. This implies that, as regards individual effects, total bilateral trade flows are influenced mainly by importing country effects. ${ }^{16}$

\section{'Dirty' Imports}

The results for 'dirty' trade are summarised in Table 3. They suggest that not allowing for specific effects, i.e. Models $A$ and $B$, importing and exporting country GDPs have positive effects, while populations, land sizes and distance all exert negative impacts on 'dirty' imports. As for the relative stringency of environmental regulations, strictness in the importing country has a strongly significant negative influence on 'dirty' trade, while strictness in the exporting country seems to be positively related to it. Note, that in this respect there is an important difference between the total and 'dirty' trade flows. In these models total imports seemed to be unaffected by environmental regulations in the exporting country, but 'dirty' imports are positively related to them. It also indicates that importing countries prefer to purchase from countries with high enviro nmental standards. This ag ain contradicts Van Beers and Van den Bergh (1997) who found no significant relationship between 'dirty' imports and the strictness of environmental regulations in the exporting countries. ${ }^{17}$

In Model $A$ adjacency, EEC and EFTA memberships are insignificant, whilst in

\footnotetext{
${ }^{16} \mathrm{By}$ and large this outcome is not sensitive to the choice of the strictness measure.

${ }^{17}$ However, as our results suggest, this might be due to the cross-sectional nature of their analysis. In Model $A$, using $R_{E S, P O P}$ or $R_{E C, P O P}$ no significant relationship between $\ln D I M P_{i j t}$ and $\ln S C_{i t}$ or $\ln S C_{j t}$ can be detected, but in Model $B$ the first relationship is significantly negative and the second is significantly positive.
} 
Table 3

OLS Estimation Results for DIMP

(GDP2 and $\left.R_{E S, G D P 2}\right)$

\begin{tabular}{|c|c|c|c|c|c|}
\hline \multirow{2}{*}{ Variable } & \multicolumn{5}{|c|}{ Specification } \\
\hline & Model A & Model B & Model C & Model D & Model E \\
\hline Constant & $18.357^{* * *}$ & $21.561^{* * *}$ & $154.599^{* * *}$ & $90.542^{* *}$ & 81.025 \\
\hline $\ln G D P_{i t}$ & $1.632^{* * *}$ & $1.925^{* * *}$ & $2.703^{* * *}$ & $2.259^{* * *}$ & 1.075 \\
\hline $\ln G D P_{j t}$ & $1.479^{* * *}$ & $1.431^{* * * *}$ & $1.524^{* * * *}$ & 0.922 & -0.259 \\
\hline $\ln P O P_{i t}$ & $-0.371^{* * *}$ & $-0.760^{* * *}$ & $-8.846^{* * *}$ & $-10.503^{* * *}$ & $-9.779^{* * *}$ \\
\hline $\ln P O P_{j t}$ & $-0.486^{* * *}$ & $-0.417^{* * *}$ & $-0.486^{* * *}$ & $5.224^{* *}$ & $5.902^{* * *}$ \\
\hline $\ln D I S T_{i j}$ & $-1.056^{* * *}$ & $-0.990^{* * *}$ & $-1.238^{* * *}$ & $-1.155^{* * *}$ & $-1.157^{* * *}$ \\
\hline $\mathrm{ADJ}_{\mathrm{ij}}$ & 0.231 & $0.334^{* * * *}$ & 0.110 & $0.212^{* * *}$ & $0.212^{* * * *}$ \\
\hline$E E C_{i j t}$ & 0.136 & $0.182^{* * * *}$ & -0.026 & -0.042 & -0.061 \\
\hline EFTA $_{i j t}$ & 0.359 & 0.0370 & $0.388^{* * *}$ & $0.303^{* *}$ & $0.327^{* *}$ \\
\hline$N A F T A_{i j t}$ & na & 0.2870 & $0.533^{* * *}$ & $0.371^{* *}$ & $0.290^{*}$ \\
\hline $\ln L A N D_{i}$ & $-0.134^{* *}$ & $-0.105^{* * *}$ & na & na & na \\
\hline $\ln L A N D_{j}$ & $-0.086^{*}$ & $-0.097^{* * *}$ & $-0.062^{* * *}$ & na & na \\
\hline $\ln S C_{i t}$ & $-0.575^{* * *}$ & $-0.512^{* * *}$ & 0.059 & 0.073 & 0.174 \\
\hline $\ln S C_{j t}$ & $0.408^{* * *}$ & $0.341^{* * *}$ & $0.214^{* * *}$ & 0.042 & 0.145 \\
\hline$D_{i}$ & na & na & - & - & - \\
\hline$D_{j}$ & na & na & na & 4 & $\begin{array}{l}4,7-9,13 \\
18,23\end{array}$ \\
\hline$D_{t}$ & na & na & na & na & $2,3,5-7$ \\
\hline Observations & 552 & 3864 & 3864 & 3864 & 3864 \\
\hline$R S S$ & & 7961.467 & 7064.248 & 5339.597 & 5301.542 \\
\hline adj. $R^{2}$ & 0.781 & 0.762 & 0.788 & 0.839 & 0.839 \\
\hline$F$-tests & df1 & $\mathrm{df} 2$ & $F$-statistic & & \\
\hline$C$ vs $B$ & 22 & 3828 & $22.099^{* * * *}$ & & \\
\hline$D$ vs $B$ & 44 & 3806 & $42.474^{* * *}$ & & \\
\hline$D$ vs $C$ & 22 & 3806 & $55.878^{* * *}$ & & \\
\hline$E$ vs $B$ & 50 & 3800 & $38.131^{* * *}$ & & \\
\hline$E$ vs $C$ & 28 & 3800 & $45.124^{* * *}$ & & \\
\hline$E$ vs $D$ & 6 & 3800 & $4.546^{* * *}$ & & \\
\hline
\end{tabular}

Note: see Table 2. 
Models C-E they are all significant in the expected (i.e. positive) direction. In Model C there is still a significant positive relationship between $\ln D I M P_{i j t}$ and $\ln S C_{j t}$, but $\ln S C_{i t}$ becomes insignificant. In Models $D$ and $E$, however, both strictness measures seem to be unimportant. ${ }^{18}$ Therefore, the conclusion is that the unobserved exporter heterogeneity and time effects have a more important role in 'dirty' trade than environmental regulations, thus Models $A$ and $B$ are mis-specified. Another important feature of Models $D$ and $E$ is that $\ln G D P_{j t}$ is insignificant, but the slope of $\ln P O P_{j t}$ is significantly positive and quite large. This means that, after having accounted for both the import ing and exporting country effects, the potential supply of the exporting country becomes unimportant, but its population exerts a strong positive effect on 'dirty' imports. Finally, this time all general $F$-tests reject the null hypothesis of jointly insignificant dummy variables. Therefore, though Models $D$ and $E$ have the same (adjusted) explanatory power, $84 \%$ approximately, the least restricted specification is statistically the most preferred one.

\section{'Footloose' Imports}

If environmental regulations have a real impact on international trade flows, their impact should be the strongest on pollution-intensive non-resource based industries, as these can be relocated with relative ease. Nevertheless, as the results in Tables 4 show, there are only two minor differences between the results for 'dirty' and 'footloose' imports. Firstly, the land size of the importing country has a significant negative effect on 'dirty' imports, but it seems to be insignificant in relation to 'footloose' imports. This might be due to the fact that natural resources play a much more important role in the competitiveness of the 'dirty' sectors in general than in the competitiveness of the 'footloose' industries. ${ }^{19}$

\footnotetext{
${ }^{18}$ There is only one exception: using $R_{E S, G D P}$ at the $10 \%$ level we can detect a positive relationship between $\ln D I M P_{i j t}$ and $\ln S C_{i t}$ in Model E.

${ }^{19}$ Nevertheles s, not much importan ce can be assign ed to this outcome since according to the results based on Model $B$ and on $R_{E C, G D P 1}, R_{E C, G D P 2}, R_{E S, P O P}$ or $R_{E C, P O P}$ the relationship between $\ln F L I M P_{i j t}$ and $\ln L A N D_{i}$ is, in fact, significantly positive.
} 
Table 4

OLS Est imation Results for FLIMP

(GDP2 and $\boldsymbol{R}_{E S, G D P 2}$ )

\begin{tabular}{|c|c|c|c|c|c|}
\hline \multirow{2}{*}{ Variable } & \multicolumn{5}{|c|}{ Specification } \\
\hline & Model A & Model B & Model C & Model D & Model E \\
\hline Constant & $19.115^{* * *}$ & $22.894^{* * *}$ & $114.392^{* * *}$ & -28.100 & -108.376 \\
\hline $\ln G D P_{i t}$ & $1.672^{* * *}$ & $1.929^{* * *}$ & $2.880^{* * *}$ & $1.895^{\text {**** }}$ & $1.197^{*}$ \\
\hline $\ln G D P_{j t}$ & $1.648^{* * *}$ & $1.705^{* * * *}$ & $1.777^{* * *}$ & 0.458 & -0.235 \\
\hline $\ln P O P_{i t}$ & $-0.554^{* * *}$ & $-0.859^{* * *}$ & $-6.447^{* * *}$ & $-10.687^{* * *}$ & $-8.007^{* * *}$ \\
\hline $\ln P O P_{j t}$ & $-0.420^{* * *}$ & $-0.499^{* * *}$ & $-0.553^{* * *}$ & $12.782^{* * *}$ & $15.411^{* * *}$ \\
\hline $\ln D I S T_{i j}$ & $-1.131^{* * *}$ & $-1.049^{* * *}$ & $-1.261^{* * *}$ & $-1.238^{* * *}$ & $-1.240^{* * *}$ \\
\hline $\mathrm{ADJ}_{\mathrm{ij}}$ & 0.256 & $0.381^{* * * *}$ & $0.216^{* * *}$ & $0.261^{* * *}$ & $0.262^{* * * *}$ \\
\hline$E E C_{i j t}$ & 0.139 & $0.251^{* * * *}$ & 0.068 & 0.027 & 0.017 \\
\hline EFTA $_{i j t}$ & 0.236 & 0.091 & $0.395^{* * *}$ & $0.362^{* * *}$ & $0.379^{* * * *}$ \\
\hline$N A F T A_{i j t}$ & na & 0.380 & $0.423^{* *}$ & $0.459^{* *}$ & $0.354^{*}$ \\
\hline $\ln L A N D_{i}$ & 0.010 & 0.024 & na & na & na \\
\hline $\ln L A N D_{j}$ & $-0.280^{* * *}$ & $-0.293^{* * *}$ & $-0.261^{* * *}$ & na & na \\
\hline $\ln S C_{i t}$ & $-0.457^{* * *}$ & $-0.469^{* * *}$ & 0.092 & 0.132 & 0.205 \\
\hline $\ln S C_{j t}$ & $0.285^{* *}$ & $0.152^{* * *}$ & 0.046 & -0.047 & 0.026 \\
\hline$D_{i}$ & na & na & $4,7,12$ & - & - \\
\hline$D_{j}$ & na & na & na & - & - \\
\hline $\mathrm{D}_{\mathrm{t}}$ & na & na & na & na & $2,3,5-7$ \\
\hline Observations & 552 & 3864 & 3864 & 3864 & 3864 \\
\hline$R S S$ & & 7746.053 & 6993.362 & 6084.913 & 6042.477 \\
\hline adj. $R^{2}$ & 0.792 & 0.783 & 0.803 & 0.827 & 0.828 \\
\hline$F$-tests & df1 & df 2 & $F$-statistic & & \\
\hline$C$ vs $B$ & 22 & 3828 & $18.728^{* * * *}$ & & \\
\hline$D$ vs $B$ & 44 & 3806 & $23.614^{* * * *}$ & & \\
\hline$D$ vs $C$ & 22 & 3806 & $25.828^{* * *}$ & & \\
\hline$E$ vs $B$ & 50 & 3800 & $21.427^{* * *}$ & & \\
\hline$E$ vs $C$ & 28 & 3800 & $21.357^{* * *}$ & & \\
\hline$E$ vs $D$ & 6 & 3800 & $4.448^{* * *}$ & & \\
\hline
\end{tabular}

Note: See Table 2. 
As regards environmental standards, in Models $A$ and $B$ the regulations in the importing country seem to have a significantly negative, while the regulations in the exporting country a significantly positive, effect on the 'footloose' bilateral trade flow s. This is again in contradiction to Van Beers and Van den Bergh (1997), who found both relationships to be significantly negative. The really important point, however, is that in Models $D$ and $E$ the specific effects again make the stringencymeasures look unimportant. ${ }^{20}$

\section{Conclusions}

This paper studied the possible impact of environmental policy on bilateral foreign trade flows. The analysis wasbased on a three-way fixed-effects model which allow s for importing country, exporting country and also for time specific effects. This model, and its variants, was estimated for a panel of 24 OECD countries over a sample period of 1990-1996. The stringency of environmental regulations was measured by six different indicators, all of which were based on either the relative energy consumption or on relative energy supply.

Although the application of the different measures led to somewhat different estimation results, it is clear from this study that the impact of environmental policy on foreign trade cannot be assessed properly without the importing and exporting country effects. Without these specific effects there seems to be a relationship between stricter regulations and foreign trade, but its significance fades as soon as both the importing and exporting country specific effects are taken into consideration. Moreover, $F$-tests suggest that these effects are jointly significant, that is they are important explanatory variables. This implies that a simple cross-sectional or naive panel-data model is mis-specified and the stringency measures, and probably also the other quantitative explanatory variables, absorb the influence of the missing specific effects.

\footnotetext{
${ }^{20}$ Using $R_{E S, G D P}$, though, both effects are significantly positive at the $10 \%$ level in Model E.
} 


\section{References}

Anderson, K. and R. Blackhurst (1992), The Greening of World Trade Issues, Harvester Wheatsheaf, New York.

Dean, J. (1992), “Trade and the Environment: A Survey of Literature”, in Low (1992b).

Jaffe, A.B., S.R. Peterson, P.R. Portney and R.B. Stavins (1995), "Environmental Regulation and the Competitiveness of U.S. Manufacturing: What does the Evidence Tell Us?", Journal of Economic Literature, 33, 132-63.

Levinson, A. (1995), "Environmental Regulations and Industry Location: International and Domestic Evidence", Manuscript, Department of Economics, University of Wisconsin.

Linnemann, H. (1966), An Econometric Study of International Trade Flows, North Holland, Amsterdam.

Low, P. (1992a), 'International Trade and the Environment", World Bank Discussion Papers, 159, World Bank, Washington D.C.

Low, P. (ed.) (1992b), “Trade Measures and Environmental Quality: The Implications for Mexico's Exports”, in Low (1992a).

OECD (1985), The Macro-Economic Impact of Environmental Expenditures, OECD, Paris.

Porter, M.E. and C. van der Linde (1995), "Towards a New Conception of the Environment-Competitiveness Relationship", Journal of Economic Perspectives, 9, 97-118.

Ratnayake, R. (1998), “Do Stringent Environmental Regulation Reduce International Competitiveness? Evidence from an Inter-Industry Analysis", International Journal of the 
Economics of Bu siness, 5, 77-96.

Sorsa, P. (1994), "Competitiveness and Environmental Standards: Some Exploratory Results", Policy Research Working Paper, The World Bank.

Stevens, C. (1993), "Synthesis Report: Environmental Policies and Industrial Competitiveness", in OECD (1993).

Tinbergen, J. (1962), Shaping the World Economy: Suggestions for an International Economic Policy, The Twentieth Century Fund, New York.

Tobey, J. (1990), "The Effects of Domestic Environmental Policies and Patterns of World Trade: An Empirical Test”, Kyklos, 43, 191-209.

Valluru, S.R.K. and E.W.F. Peterson (1997), “The Impact of Environmental Regulations on World Grain Trade", Agribusiness, 13, 261-272.

Van Beers, C. and J.C.J.M van den Bergh (1996), “An Overview of Methodological Approaches in the Analysis Trade and Environment", Journal of World Trade, 30, 143-167.

Van Beers, C. and J.C.J.M van den Bergh, J.C.J.M. (1997), “An Empirical Multi-Country Analysis of the Impact ofEnvironmental Regulations on Foreign Trade Flows", Kyklos, 50, 29-46.

Xing, Y. and C.D. Kolstad (1996), "Environment and Trade: A Review of Theory and Issues", Working Papers in Economics, 02/96, University of California. 